\title{
OPTIMUM STERILIZATION: A COMPARATIVE STUDY BETWEEN AVERAGE AND SURFACE QUALITY
}

\author{
C.L.M. SILVA, F.A.R. OLIVEIRA', and P.A.M. PEREIRA \\ Escola Superior de Biotecnologia - UCP \\ Rua Dr. António Bernardino de Almeida \\ 4200 Porto, Portugal \\ and \\ M. HENDRICKX \\ Katholieke Universiteit Leuven \\ Laboratory of Food Technology \\ Kardinaal Mercierlaan 92 \\ 3001 Heverlee, Belgium
}

\begin{abstract}
Sterilization temperatures to maximize volume average or surface quality retention were calculated for one-dimensional conduction heating foods as a function of (1) Food Properties, (2) Processing Conditions and (3) Processing Criteria. A target lethality at the least-lethality point was used as a constraint, and optimal temperatures were qualitatively and quantitatively compared for equal design variables.

Average quality optimum conditions depend linearly on the inverse square of the $D_{\text {refq }}$-value for the quality factor. These conditions do not vary linearly with all the other influential variables, opposite to what had been observed for surface quality. Optimum temperature for maximum average quality is always higher than the corresponding one for surface quality, but the difference is not constant. A systematic approach to the dependence of average quality optimal conditions on all the relevant parameters was carried out and quantitative relations were obtained. Optimum average quality retention is independent of surface heat transfer resistance.
\end{abstract}

'Author to whom correspondence should be addressed. 


\section{INTRODUCTION}

The mathematical description of microorganisms thermal degradation kinetics together with an accurate model of heat flow into a conduction heating product allows the theoretical assessment of the sterilization process (Teixeira et al. 1969a). If an objective function is specified, it is possible to optimize the sterilization conditions (Teixeira et al. 1969b). Holdsworth (1985) and Silva et al. (1993) have presented extensive critical reviews on the modelling of optimal processing conditions for sterilized prepackaged foods.

Several objective functions, such as minimization of energy consumption and economic costs (Barreiro et al. 1984) and formation of toxic compounds (Lund 1982), can be considered. However, regarding consumers interests, the maximization of nutrients and quality-attributes retention is usually the most important goal (Silva et al. 1992b; Ridgway and Brimelow 1990).

Depending on the quality parameter to optimize two options can be considered (Ohlsson 1980a): maximizing quality retention in terms of (1) surface (Ohlsson 1980a,b,c; Hendrickx et al. 1990, 1992a,b, 1993; Silva et al. 1992b) or (2) volume average (Ohlsson 1980a,b,c; Teixeira et al. 1969b, 1975; Thijssen et al. 1978; Saguy and Karel 1979; Thijssen and Kochen 1980; Martens 1980; Nadkarni and Hatton 1985; Tucker and Holdsworth 1990, 1991; Banga et al. 1991).

Although in this research field several works have been published, few attempted to develop a consistent relationship between optimal conditions and all influential variables. Hendrickx et al. $(1990,1992 a, b, 1993)$ and Silva et al. (1992a) developed generalized semi-empirical formulae to calculate optimal temperatures for maximum surface quality as a function of all relevant variables: target sterility value at the least-lethality point, reduced Fourier number or heat penetration parameter, z-value for quality factor thermal degradation kinetics, Biot number, geometry and initial product temperature. These equations are multilinear regressions and have also been applied to case studies such as finite cylindrical can (Hendrickx et al. 1992b). However, for average quality optimization a similar work is lacking. Ohlsson (1980a,b,c) detected a linear relationship between optimal temperatures to minimize volume average cookvalue and the heat penetration parameter, $\mathrm{f}_{h}$, for infinite slab and finite cylinder conduction heating foods. However, the range of values simulated for $f_{h}$ was narrow. Furthermore, when the average cook-value is used as objective function, the influence of the reference D-value for the quality attribute kinetics on optimal conditions was disregarded (Silva et al. 1992a).

With the exception of Ohlsson (1980a,b,c) and Banga et al. (1991), few authors compared average and surface quality optimum conditions. Ohlsson $(1980 \mathrm{a}, \mathrm{b})$ stated that for infinite slab and finite cylinder geometries optimum temperatures for minimum average cook-value were approximately $7.5-10 \mathrm{C}$ and 
$2.5 \mathrm{C}$ above the ones for minimum surface quality degradation, respectively. However, the range of cases studies carried out was very limited and as referred above the objective function used to maximize the average quality retention was not the most suitable (Silva et al. 1992a). Banga et al. (1991) studied the influence of optimum variable retort temperature profile on average quality and concluded that this policy does not offer significant advantages over constant retort temperature. On the contrary, when an optimized variable retort temperature is applied the surface quality can be significantly improved.

Therefore, the main objectives of this work were (1) the development of a relationship between optimal constant temperatures to maximize average quality retention and all the influential variables (2) to study the effect of the sterilization conditions on the final product quality, and (3) a comparative study between average and surface quality optimal constant temperatures for equal relevant variables.

\section{MATERIALS AND METHODS}

Optimal sterilization temperatures to minimize average quality degradation of conduction heating foods were calculated as a function of all relevant variables. A calculation approach similar to the one presented by Silva et al. (1992b) was applied.

A first order inactivation kinetics (both for microorganisms and quality factors) was assumed, and described with a decimal reduction time $\left(D_{\text {ref }}\right)$ and a $\mathrm{z}$-value. The $\mathrm{z}$-value for thermal death of microorganisms $\left(\mathrm{z}_{\mathrm{m}}\right)$ was set equal to 10C (Pflug and Odlaug 1978) and optimal conditions were determined for a range of $D_{\text {refq }}$ and $z_{q}$ values, including all the available data for quality attribute kinetics of thermal destruction (Lund 1975, 1977) (Table 1).

An explicit finite-difference numerical method, with a noncapacitance surface node (Chau and Gaffney 1990), was used to simulate the heat transfer into the food. One-dimensional geometries only were considered, i.e., infinite slab, infinite cylinder and sphere. A constant and uniform overall heat transfer coefficient at the product surface accounted for the packaging material and heating medium thermal resistance. The food was assumed as homogeneous, isotropic and with uniform initial temperature $\left(\mathrm{T}_{\mathrm{o}}\right)$. The heating medium time-temperature profile was a step function with a cooling temperature of $20 \mathrm{C}$. The initial product temperature and heating medium come-up-time were set equal to $10 \mathrm{C}$ and zero, respectively, since these parameters are not expected to affect optimal temperatures (Silva et al. 1992a).

The optimization procedure used a target $\mathrm{F}_{\mathrm{o}}$-value $\left(\mathrm{F}_{\mathrm{t}}\right)$ at the slowest product heating point as a constraint

$$
\left.F_{0}=\int_{0}^{t} 10^{\left(T_{c}-T^{r e f m}\right.}\right)^{/ z} \mathrm{~m} d t
$$


TABLE 1.

RANGE OF VARIABLE VALUES USED TO CALCULATE OPTIMAL STERILIZATION TEMPERATURES

\begin{tabular}{|c|c|c|}
\hline Variable & minimum value & maximum value \\
\hline Drefa $(\min )$ & 5 & 905 \\
\hline $\mathrm{za}(\mathrm{C})$ & 15 & 45 \\
\hline $\mathrm{RF}\left(\mathrm{s}^{-1}\right)$ & $2.844 \times 10^{-5}$ & $6.400 \times 10^{-3}$ \\
\hline fh (min) sphere & 0.608 & 596.3 \\
\hline inf. cyl. & 1.036 & 527.6 \\
\hline inf. sab & 2.430 & 1163.8 \\
\hline $\mathrm{Bi}$ & 0.9 & $\infty$ \\
\hline$F_{t}(\min )$ & 3 & 15 \\
\hline
\end{tabular}

and the objective function was the volume average quality retention,

$$
(N / N o)_{\text {ave }}-\frac{1}{V} \int_{0}^{V} 10-\frac{1}{D_{\text {reta }}} \int_{0}^{t} 10{ }^{\left(T-T_{\text {reta }}\right) / z_{a}} d V^{\prime}
$$

This is the most adequate function when the average quality is to be maximized (Silva et al. 1992a).

The range of influential variable values used to determine optimal conditions included a wide range of practical sterilization processes (Silva et al. 1992b) (Table 1). Case studies for which optimum holding temperature (design variable) was over $160 \mathrm{C}$, or final average retention was less than $10 \%$, were considered out of practical interest.

Considering an infinite surface heat transfer coefficient, the effect of the $D_{\text {rer }}$-value for the quality factor on optimal conditions was studied; 7680 optimization case-studies were calculated, resultant from the combination of 3 geometries, 5 values for $F_{t}, 8$ values for $\mathbf{R F}, 4$ values for $z_{q}$, and 16 values for $D_{\text {refq. }}$. To study the influence of surface resistance to heat transfer, a second 
database of 6048 case studies ( $7 \mathrm{D}_{\text {refq }}, 3 \mathrm{~F}_{\mathrm{t}}, 4 \mathrm{RF}, 4 \mathrm{z}_{\mathrm{q}}, 6 \mathrm{Bi}$ and 3 geometries) was generated. The selection of the different number of levels for each of the relevant variables was based on previous authors' experience (Hendrickx et al. 1990, 1993; Silva et al. 1992b). Biot numbers higher than 0.9 only were used, because at lower values the optimal temperature tends to infinity.

Optimal holding temperatures to maximize surface quality were also calculated using generalized regression equations presented by Hendrickx et al. (1993) and Silva et al. (1992b) (Table 2).

TABLE 2.

GENERALIZED (SEMI)-EMPIRICAL EQUATIONS OF OPTIMAL STERILIZATION TEMPERATURES, TO MAXIMIZE SURFACE QUALITY, AS A FUNCTION OF RELEVANT VARIABLES

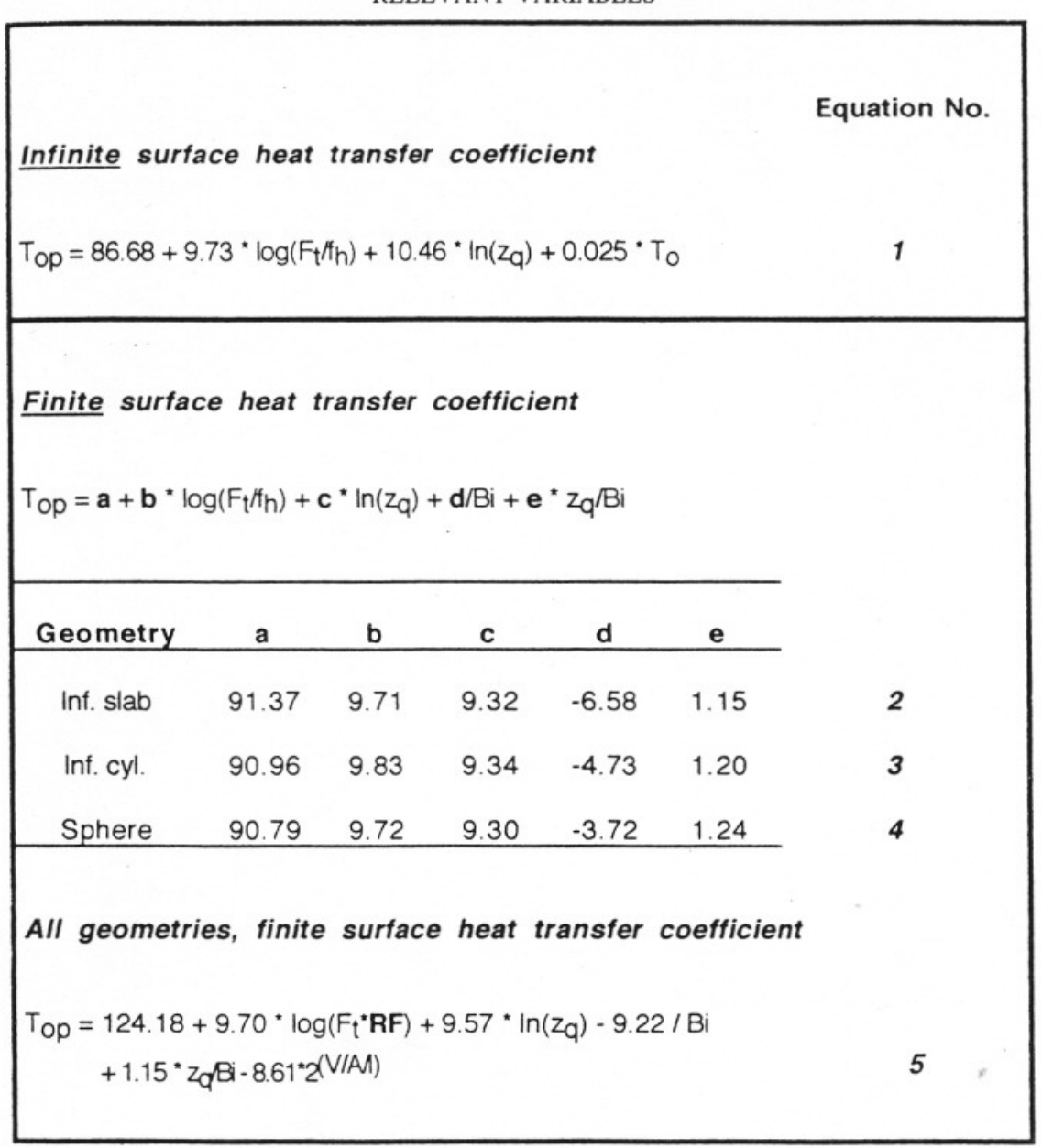




\section{RESULTS AND DISCUSSION}

\section{Effect of $D_{\text {refq }}-$ Value}

Typical results for the dependence of optimal temperature for volume average quality on $\mathrm{D}_{\text {refq }}$-value are illustrated in Fig. 1 and 2. For $\mathrm{D}_{\text {refq }}$-values smaller than approximately $300 \mathrm{~min},\left(\mathrm{~T}_{\mathrm{op}}\right)^{\text {ave }}$ is very sensitive to small variations of this parameter (Fig. 1). This range of degradation rates corresponds to texture and color kinetics, which are not so resistant to thermal treatment (Lund 1975, 1977). For this type of products the sterilization must be processed at higher temperatures and shorter processing times. This effect depends on geometry, being minimal for spheres and maximal for infinite slab containers (Fig. 2). The heat transfer into an infinite slab package is slower, therefore to minimize the volume average quality degradation in this type of containers the sterilization must be accelerated. Furthermore, the volume integrated quality retention approaches more the quality at the surface for a spherical geometry. For $\mathrm{D}_{\text {refq- }}$-values larger than $300 \mathrm{~min}$ (e.g., vitamins), the optimum holding temperature is not affected by this variable.

The dependence of optimal temperature on $\mathrm{D}_{\text {refq }}$ can be expressed by a linear relation between $\left(\mathrm{T}_{\mathrm{op}}\right)^{\text {ave }}$ and $1 / \mathrm{D}_{\text {refq }}{ }^{2}$. The parameters of this relation are a function of the $\mathrm{F}_{t}$-value (Fig. 1), Reduced Fourier number (RF) or heat penetration parameter $\left(f_{h}\right), z_{q}$-value and geometry (Fig. 2). Optimal temperature is higher and more sensitive to the $\mathrm{D}_{\text {refq }}$-value for sterilizations with long processing times (i.e., process with larger $\mathrm{F}_{\mathrm{t}}$-value and heat penetration parameter $f_{h}$ or for infinite slab containers).

\section{Effect of Product Heating Rate, $\mathbf{z}_{\mathrm{q}}$-Value and $\mathrm{F}_{\mathrm{t}}$-Value}

The influence of $\mathbf{R F}$ or $\mathrm{f}_{\mathrm{h}}, \mathrm{F}_{\mathrm{t}}$-value and $\mathrm{z}_{\mathrm{q}}$-value on optimum processing temperature, to minimize volume average quality degradation for constant $D_{\text {refa }}$-value, can be concluded from Fig. 3, 4 and 5.

If the heating rate is not too slow, optimum holding temperature decreases with increasing heat penetration parameter $f_{h}$. Products with low thermal diffusivity or large heat transfer length must be processed with smoother conditions. However, when the heating rate is very small (e.g., big containers) optimum temperature increases because an increase of the surface quality thermal degradation guarantees an higher volume average quality retention. This effect is more evident when the quality attribute kinetics is less sensitive to temperature variations (i.e., higher $\mathrm{z}_{\mathrm{q}}$-values) (Fig. 3).

For low values of the heat penetration parameter $f_{h}$ (or large values of $\mathbf{R F}$ ) optimal temperature to maximize average retention is $\log$-linear with $\mathrm{f}_{\mathrm{h}}$ or $\mathbf{R F}$, where for slow heating rate foods (large $f_{h}$ or small $\mathbf{R F}$ ) an inversion is observed and optimum tends to increase (Fig. 3). This effect is more important 


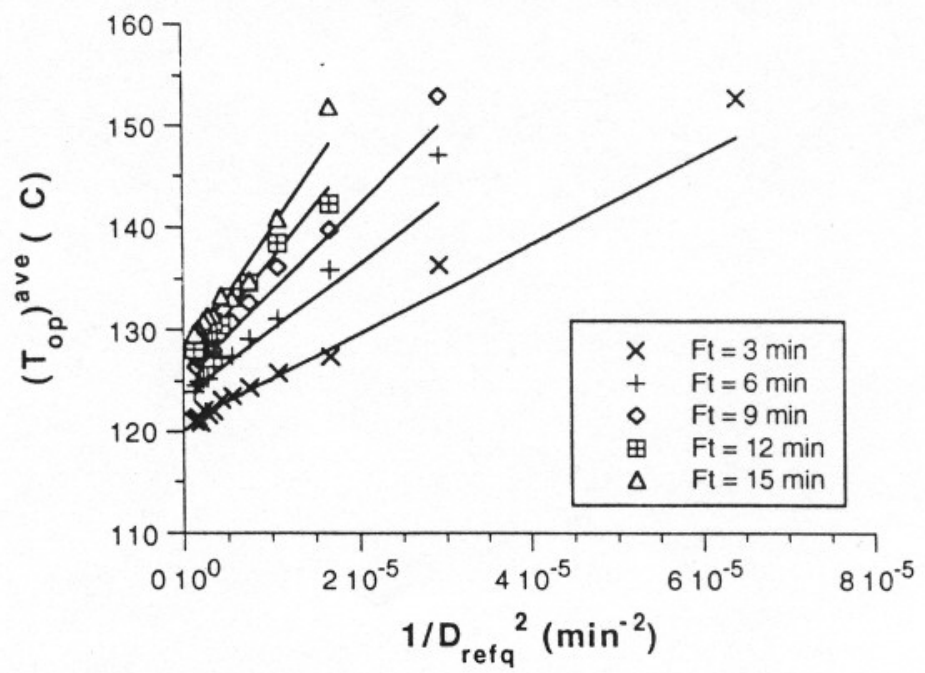

FIG. 1. OPTIMAL PROCESSING TEMPERATURE TO MAXIMIZE AVERAGE QUALITY RETENTION, FOR AN INFINITE SLAB PRODUCT, AS A FUNCTION OF $D_{\text {refq }}$-VALUE FOR $\mathrm{z}_{\mathrm{q}}=35 \mathrm{C}, \mathbf{R F}=6.17 \mathrm{E}-5 \mathrm{~s}^{-1}$ AND Bi $=\infty$

Lines represent results predicted by regression equations in Table 3.

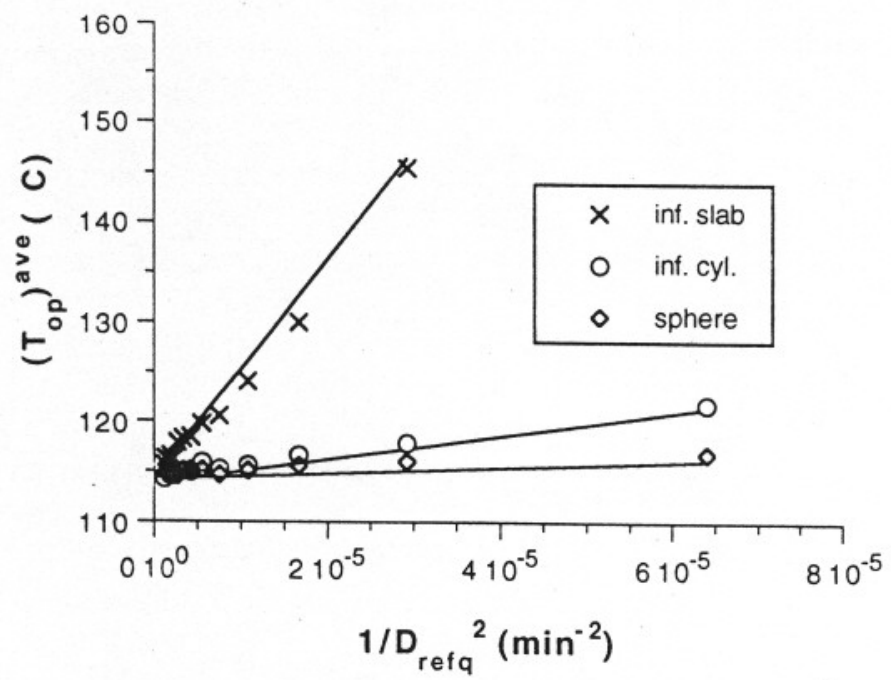

FIG. 2. OPTIMAL PROCESSING TEMPERATURE TO MAXIMIZE AVERAGE QUALITY RETENTION, AS A FUNCTION OF $D_{\text {refq }}$-VALUE FOR $F_{t}=9 \mathrm{MIN}, \mathrm{z}_{4}=25 \mathrm{C}$ AND $\mathbf{R F}=2.84 \mathrm{E}-5 \mathrm{~s}^{-1}$ AND $\mathrm{Bi}=\infty$

Continuous lines represent results predicted by regression equations in Table 3 . 


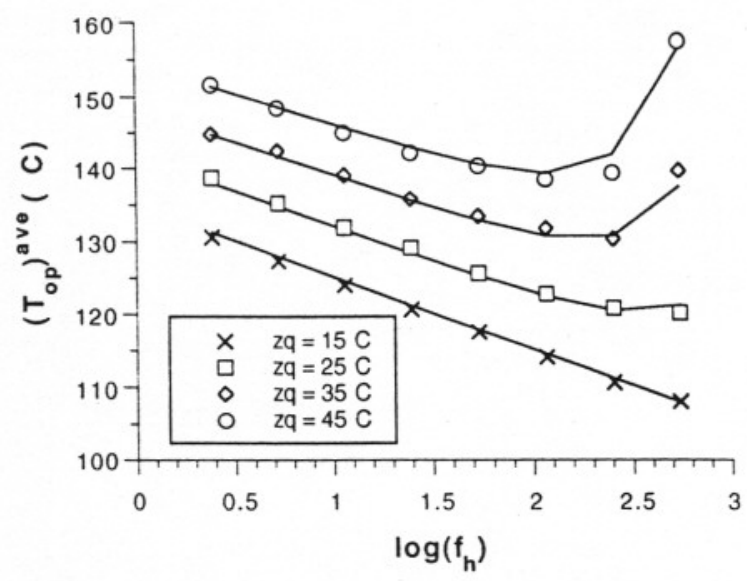

FIG. 3. OPTIMAL PROCESSING TEMPERATURE TO MAXIMIZE AVERAGE QUALITY RETENTION, FOR AN INFINITE SLAB PRODUCT, AS A FUNCTION OF $\mathrm{f}_{\mathrm{h}}$ FOR $\mathrm{D}_{\text {refq }}=485 \mathrm{MIN}, \mathrm{F}_{\mathrm{t}}=12 \mathrm{MIN}$ AND Bi $=\infty$

Continuous lines represent results predicted by regression equations in Table 3 .

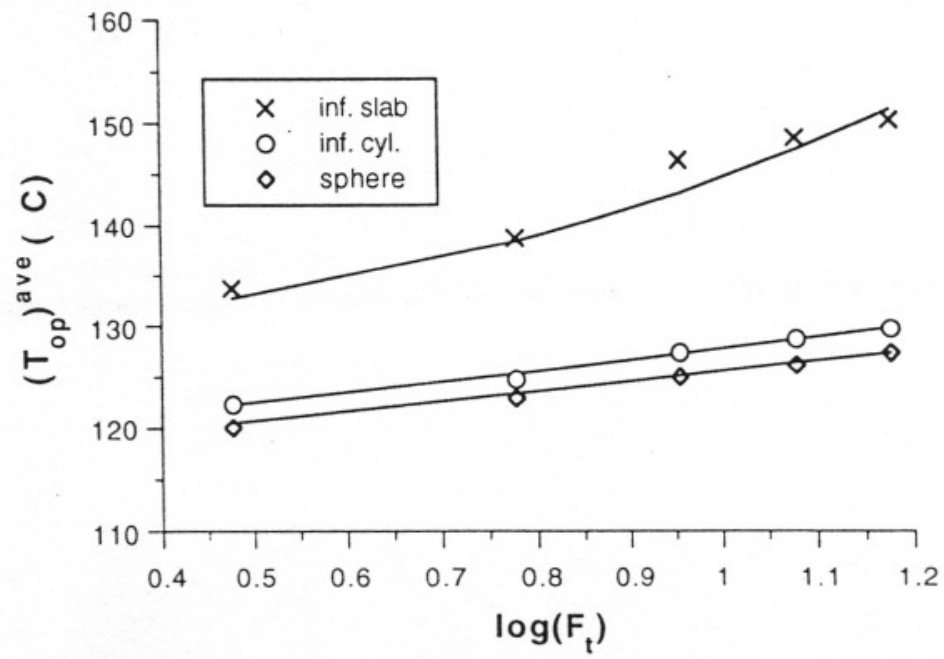

FIG. 4. OPTIMAL PROCESSING TEMPERATURE TO MAXIMIZE AVERAGE QUALITY RETENTION AS A FUNCTION OF Fit-VALUE FOR $D_{\text {ref }}=605 \mathrm{MIN}, \mathrm{z}_{4}=45 \mathrm{C}$,

$$
\mathbf{R F}=2.84 \mathrm{E}-5 \mathrm{~s}^{-1} \text { AND Bi }=\infty
$$

Continuous lines represent results predicted by regression equations in Table 3 . 


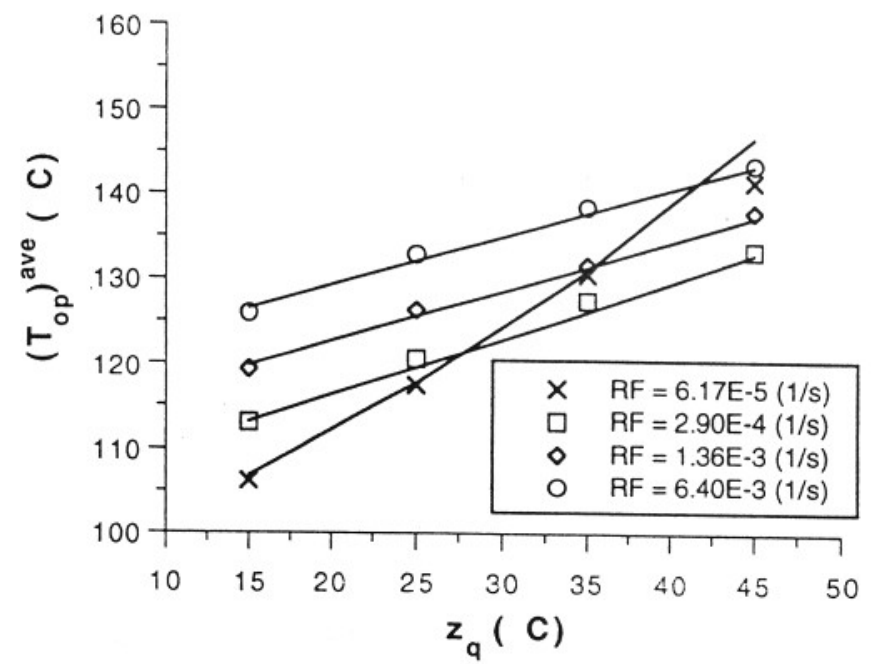

FIG. 5. OPTIMAL PROCESSING TEMPERATURE TO MAXIMIZE AVERAGE QUALITY RETENTION, FOR AN INFINITE CYLINDER PRODUCT, AS A FUNCTION OF $z_{4}$-VALUE FOR $D_{\text {refq }}=65 \mathrm{MIN}, \mathrm{F}_{\mathrm{t}}=3 \mathrm{MIN}$ AND Bi $=\infty$

Continuous lines represent results predicted by regression equations in Table 3.

for larger $\mathrm{z}_{\mathrm{q}}$-values, and infinite slab geometries. A log-linear relation had already been observed between optimum temperature to minimize surface quality degradation, although for the whole range of $\mathrm{f}_{\mathrm{h}}$ values (Hendrickx et al. 1990, 1993; Silva et al. 1992b).

Optimum temperatures to minimize average quality degradation increase with increasing target $\mathrm{F}_{\mathrm{o}}$-value (Fig. 4). For some conditions this relation is linear, but this may not be taken as a general rule. For instance, in the case of an infinite slab, optimal temperature is more sensitive to increases in the target $\mathrm{F}_{\mathrm{o}}$-value for products that require an high $\mathrm{F}_{\mathrm{t}}$-value.

Higher $\mathrm{z}_{\mathrm{q}}$-values correspond to higher $\left(\mathrm{T}_{\mathrm{op}}\right)^{\text {ave }}$ temperatures (Fig. 5). This should be expected, since a higher $\mathrm{z}_{\mathrm{q}}$-value represents a more thermal-resistant quality factor. It can be noticed once more that the product heat transfer rate has an important role: for low $\mathbf{R F}$ values (slow heating rate) the influence of $\mathbf{z}_{\mathrm{q}}$ on optimal temperatures is very significant (Fig. 5).

It can be observed that the total processing time $\left(t^{\prime}\right)$, corresponding to the optimum holding temperature, when the resistance to heat transfer at the surface is neglectable is insensitive to the $\mathrm{F}_{\mathrm{t}}$-value (Fig. 6). This is an important rule of thumb, already reported for optimum surface quality conditions (Silva et al. 1992b). This means that if an optimized process for a given product with a given $F_{t}$ is known, the optimal process for another $F_{t}$ requirement will have the same processing time. The optimal processing temperature for this case can then be easily obtained. Furthermore, as it should be expected, optimum total 


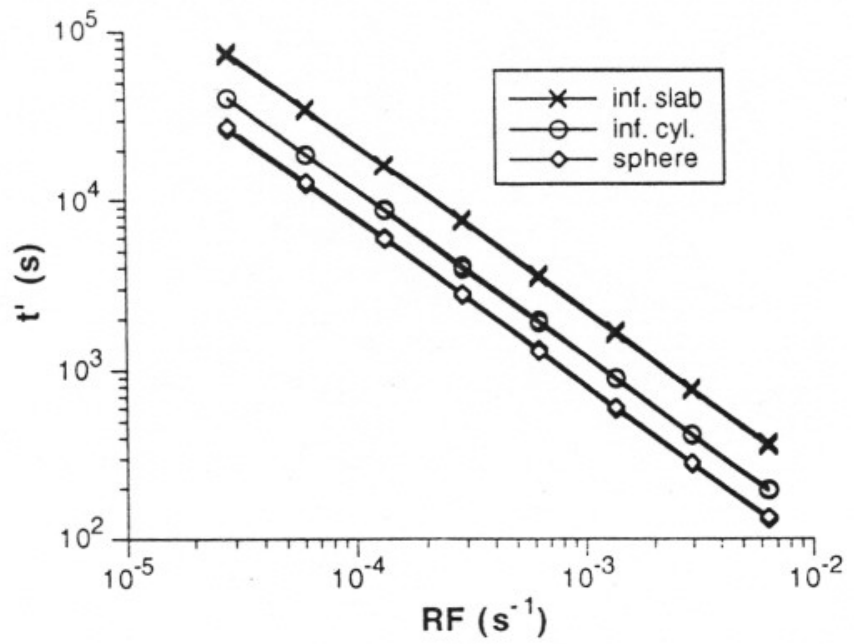

FIG. 6. OPTIMAL TOTAL PROCESSING TIME AS A FUNCTION OF RF FOR TARGET $\mathrm{F}_{\mathrm{o}}$-VALUE $=3,6,9,12$ AND $15 \mathrm{MIN}, \mathrm{D}_{\text {refq }}=905 \mathrm{MIN}, \mathrm{z}_{\mathrm{q}}=15 \mathrm{C}$ AND Bi $=\infty$

processing time $\left(\mathrm{t}^{\prime}\right)$ decreases for faster heating foods containers [i.e., higher Reduced Fourier number (RF) and spherical products].

It is also very important to note that average quality retention does not change linearly with optimum temperature. This implies that for some conditions there is a wide range of temperatures that can produce quite acceptable products, while for others, meeting the optimum temperature is very important. Particularly average quality retention decreases or increases with the $\mathrm{z}_{\mathrm{q}}$-value depending on the value of the Reduced Fourier number (RF) (Fig. 7). When the heating rate is high (large RF value) optimum temperatures are high (Fig. 3) and the retention increases with the $\mathrm{z}$-value for the quality attribute. On the contrary, if the product heats very slowly, optimal temperature increases if the $z_{q}$-value is large, but the average quality retention decreases.

\section{Effect of Surface Resistance to Heat Transfer}

It was concluded that optimal average quality temperatures decrease for smaller surface heat transfer resistance (large Biot numbers) conditions (Fig. 8). Small Bi numbers imply slower heat transfer rate to the least-lethality point and the sterilization must be accelerated using higher temperatures. A linear relation was observed for $\left(\mathrm{T}_{\mathrm{op}}\right)^{\text {ave }}$ as a function of $\mathrm{c}_{1} / \mathrm{Bi}+\mathrm{c}_{2}{ }^{*} \mathrm{z}_{\mathrm{q}} / \mathrm{Bi}$, where $\mathrm{c}_{1}$ and $\mathrm{c}_{2}$ are constants dependent on the geometry. This type of relation had also been detected for optimal temperature to maximize surface quality (Silva et al. 1992a) (Table 2). 


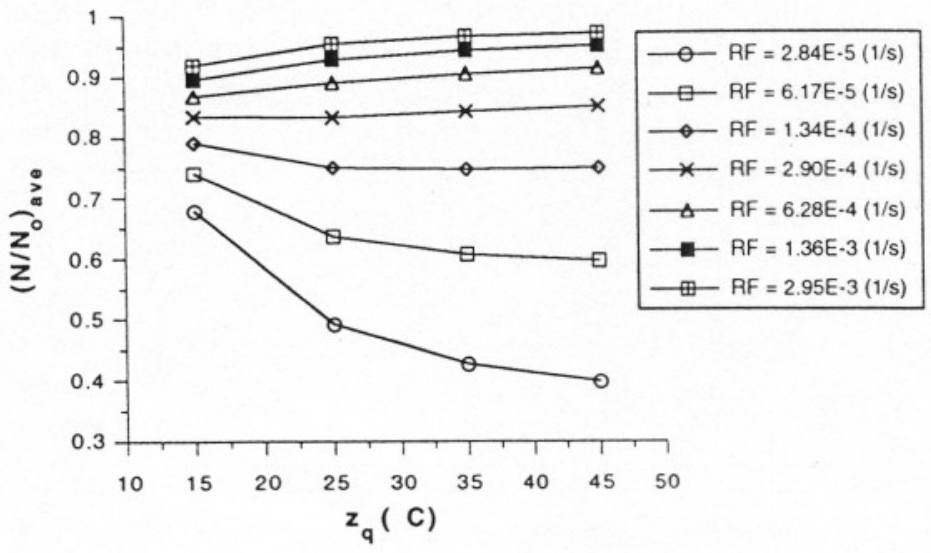

FIG. 7. AVERAGE QUALITY RETENTION, FOR A SPHERICAL PRODUCT, AS A FUNCTION OF $z_{q}$-VALUE FOR $D_{\text {refq }}=305 \mathrm{MIN}, \mathrm{F}_{\mathrm{t}}=15 \mathrm{MIN}$ AND Bi $=\infty$

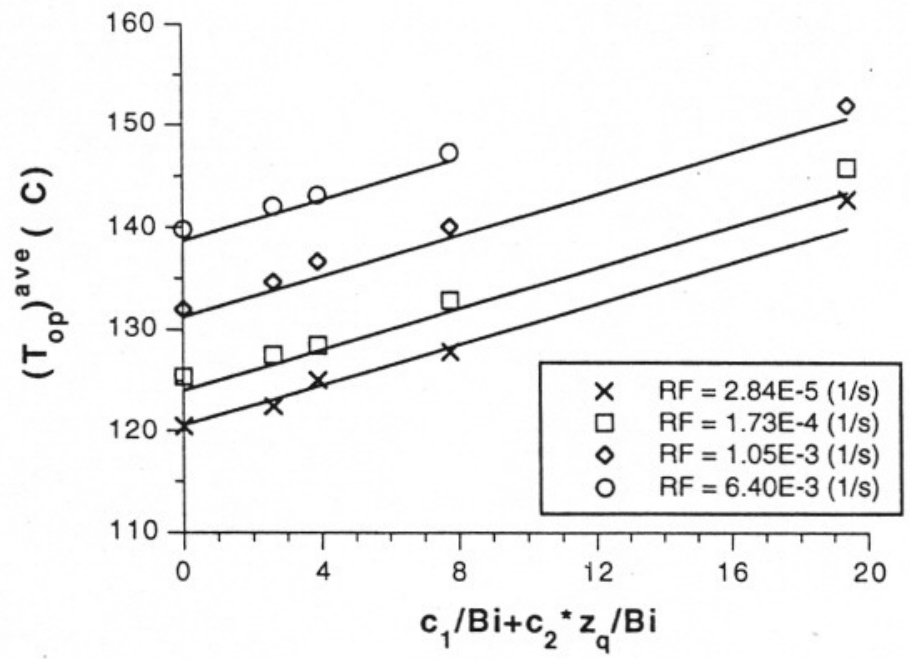

FIG. 8. OPTIMAL PROCESSING TEMPERATURE TO MAXIMIZE AVERAGE QUALITY RETENTION, FOR AN INFINITE SLAB PRODUCT, AS A FUNCTION OF $\mathrm{c}_{1} / \mathrm{Bi}+\mathrm{c}_{2}{ }^{*} \mathrm{z}_{q} / \mathrm{Bi}$

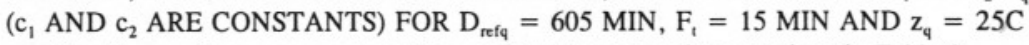
Continuous lines represent results predicted by regression equations in Table 3. 
Optimum average quality retention is insensitive to the surface Biot number (Fig. 9). Therefore, although different surface resistances to heat transfer lead to different optimal temperature, working at optimal conditions allows the same optimum average retention. This means that a conduction heating food packed in metal or plastic containers, sterilized in static or agitated retorts operated by steam or pressurized water do not have different volume average quality retention, if processed at optimal conditions. This has obviously implications in terms of costs. However, plastic containers, agitated and pressurized water retorts may offer significant advantages in terms of the final uniformity in quality retention distribution. These statements need experimental verification.

\section{A Systematic Approach}

For each geometry, it was possible to express the influence of all the variables $\left(D_{\text {refq }}, f_{h}\right.$ or $\mathbf{R F}, F_{t}, z_{q}$ and $\left.B i\right)$ on $\left(T_{o p}\right)^{\text {ave }}$ as a multilinear relationship (STATA, 1990). Multiple linear regressions were performed (Table 3), using the heat penetration parameter $\left(f_{h}\right)$ or the Reduced Fourier number (RF) and considering separately infinite and finite surface heat transfer coefficients. Continuous lines in Fig. 1, 2, 3, 4, 5 and 8 were calculated using the formulae presented in Table 3. Using these expressions for $\left(\mathrm{T}_{\mathrm{op}}\right)^{\text {ave }}$, a formula method may then be used to evaluate the corresponding processing time.

Silva et al. (1992a) introducing the ratio: V/(A*1) were able to develop a regression equation for $\left(\mathrm{T}_{\mathrm{op}}\right)^{\text {surf }}$ valid for the three one-dimensional geometries.

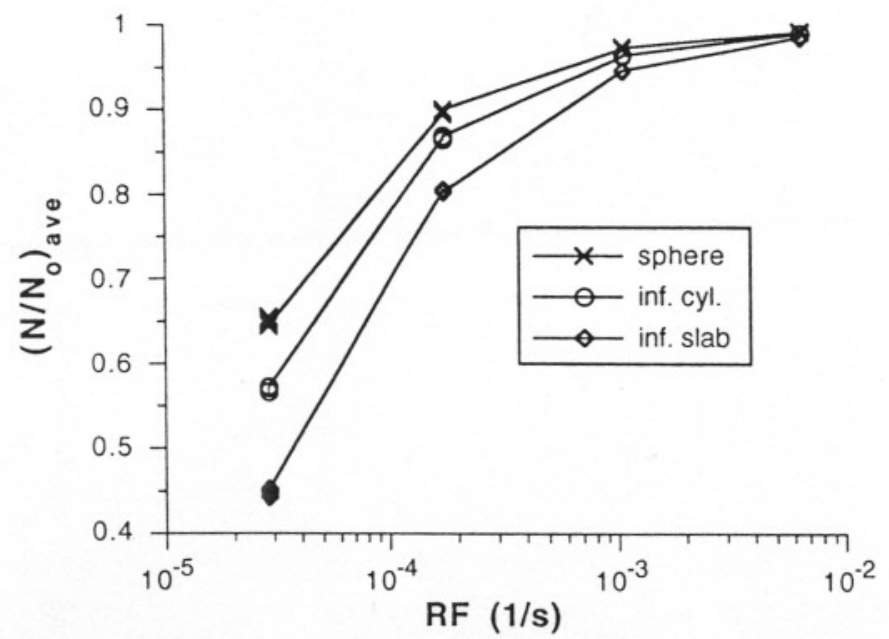

FIG. 9. AVERAGE QUALITY RETENTION AS A FUNCTION OF RF FOR Bi $=0.9,2,5,10,15$ AND $\infty, D_{\text {refq }}=455 \mathrm{MIN}, \mathrm{F}_{1}=3 \mathrm{MIN}$ AND $z_{4}=45 C$ 
TABLE 3.

GENERALIZED (SEMI)-EMPIRICAL EQUATIONS OF OPTIMAL STERILIZATION TEMPERATURES, TO MAXIMIZE AVERAGE QUALITY, AS A FUNCTION OF RELEVANT VARIABLES

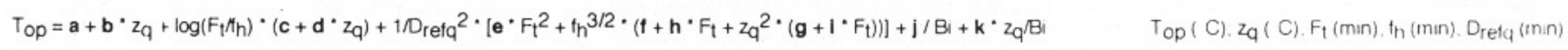

\begin{tabular}{|c|c|c|c|c|c|c|c|c|c|c|c|c|c|}
\hline Geon & try & a & b & c & d & e & $f$ & g & h & $\mathbf{i}$ & j & k & $\begin{array}{l}\text { corr. } \\
\text { coef. }\end{array}$ \\
\hline \multirow[t]{2}{*}{ Int. slab } & \multirow{2}{*}{$\begin{array}{r}h_{\infty} \\
h_{\text {finite }} \\
\end{array}$} & 113.9 & 0.701 & 10.75 & -0.047 & 45.02 & -16.21 & 0.061 & .3 .10 & 0016 & & & 0992 \\
\hline & & 113.9 & 0.707 & 10.82 & -0.061 & 38.87 & -1018 & 0.029 & .200 & 0010 & .747 & 198 & 0987 \\
\hline \multirow[t]{2}{*}{ Int. cyl. } & \multirow{2}{*}{$\begin{array}{r}h_{\infty} \\
h_{\text {finite }}\end{array}$} & 113.4 & 0.571 & 10.38 & .0 .024 & 0.730 & -6.04 & 0031 & .0799 & 0005 & & & 0993 \\
\hline & & 1138 & 0.552 & 10.40 & -0.027 & 0.809 & .5 .22 & 0.019 & -1.03 & 0004 & .7 .74 & 187 & 0993 \\
\hline \multirow[t]{2}{*}{ Sphere } & \multirow{2}{*}{$\begin{array}{r}h_{\infty} \\
h_{\text {finite }}\end{array}$} & 112.9 & 0.515 & 10.20 & -0.015 & 0.273 & .274 & 0019 & .0 .156 & 0002 & & & 0996 \\
\hline & & 113.4 & 0.478 & 9.97 & -0.011 & 0.335 & -1.91 & 0.011 & .0 .239 & 0002 & .941 & 194 & 0993 \\
\hline
\end{tabular}

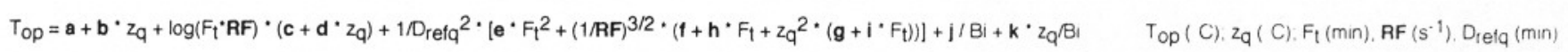

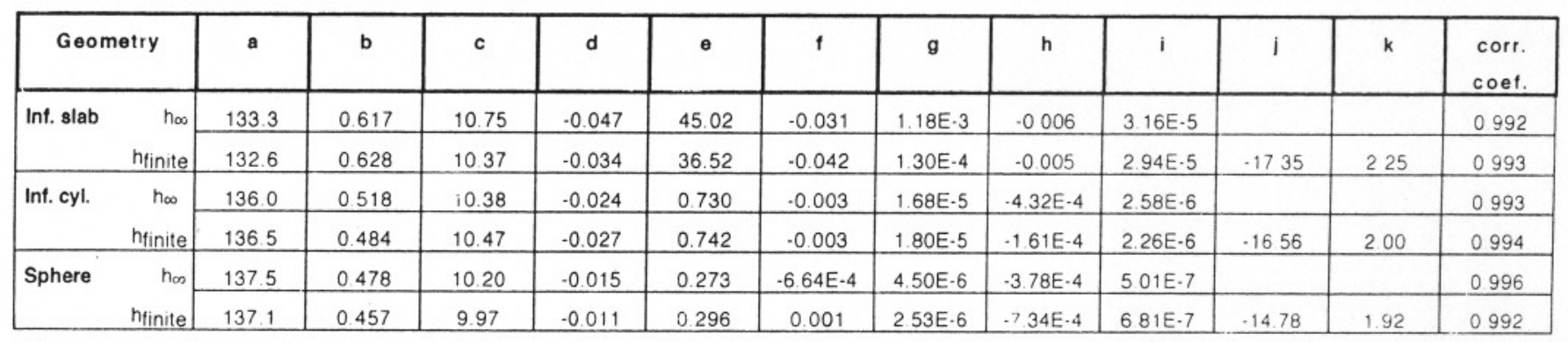


The same approach was tried, and two equations (in terms of $f_{h}$ or RF) were obtained:

$$
\begin{aligned}
& \left(T_{\text {op }}\right)^{\text {ave }}=a+z_{q^{*}}\left(b+c^{*} V /(A . I)\right)+\log \left(F_{t} / t_{h}\right) *\left(d+e^{*} V /(A . I)+f^{*} z_{q}\right)+ \\
& 1 / \text { Prefq }^{2} \cdot\left[\mathrm{Ft}_{\mathrm{t}}^{2} \cdot(\mathbf{g}+\mathrm{h} \cdot \mathrm{V} /(\mathrm{A} . \mathrm{I}))+\mathrm{fh}^{3 / 2} \cdot\left(\mathbf{i}+\mathrm{j} \cdot \mathrm{z}_{\mathrm{q}}{ }^{2}+\mathrm{F}_{\mathrm{t}} \cdot(\mathbf{k}+\mathrm{I} \cdot \mathrm{V} /(\mathrm{A} . \mathrm{I})+\right.\right. \\
& \left.\left.\left.z_{q}^{2} \cdot(m+n \cdot V /(A . I))\right)\right)\right]+o / B i+p \cdot z_{q} / B i \\
& \left(T_{\text {op }}\right)^{\text {ave }}(\mathrm{C}): z_{q}(C): F_{t}(\min ) ; f_{h}(\min ) ; D_{\text {refq }}(\min )
\end{aligned}
$$

and

$$
\begin{aligned}
& \left.\left(T_{\text {op }}\right)^{\text {ave }}=a+z_{q}^{*}\left(b+c^{*} V /(A . I)\right)+\log \left(F_{t^{*}} R F\right)\right)^{*}\left(d+e^{*} V /(A . I)+f^{*} z_{q}\right)+ \\
& 1 / D_{\text {refq }}{ }^{2} \cdot\left[F_{t}{ }^{2} \cdot(\mathbf{g}+\mathbf{h} * V /(A . I))+(1 / R F)^{3 / 2} \cdot\left(\mathbf{i}+j^{*} z_{q^{2}}+F_{t} \cdot(k+l \cdot V /(A . I)+\right.\right. \\
& \left.\left.\left.z_{q}^{2} \cdot(m+n \cdot V /(A . I))\right)\right)\right]+o / B i+p \cdot z q / B i \\
& \left(T_{\text {op }}\right)^{\text {ave }}(\mathrm{C}) ; z_{q}(C) ; F_{t}(\min ): R F\left(s^{-1}\right) ; D_{\text {refq }}(\min )
\end{aligned}
$$

where the values for the constants are shown in Table 4.

Equations (3) and (4) and equations in Table 3 allow calculation of optimal temperatures without the need of computer modelling. However, the user must be aware of the assumptions used in its development in order to avoid misuse. Equations (3) and (4) may be applicable to any finite geometry, however validation is required (Silva et al. 1994).

\section{Comparative Study Between Average and Surface Quality}

In order to compare optimal conditions for maximum volume average quality with the corresponding for maximum surface quality, plots of $\left(\mathrm{T}_{\mathrm{op}}\right)^{\text {ave }}-\left(\mathrm{T}_{\mathrm{op}}\right)^{\text {surf }}$ as a function of $\mathrm{D}_{\text {refq }}, \mathrm{f}_{\mathrm{h}}, \mathrm{F}_{\mathrm{t}}, \mathrm{z}_{\mathrm{q}}$ and $\mathrm{Bi}$ (Fig. 10,11 12, 13 and 14) were generated. Average quality optimal temperatures are always higher than optimal temperatures for surface quality, but this difference depends on the values of all the influential variables. Ohlsson $(1980 \mathrm{a}, \mathrm{b})$ stated that this difference for an infinite slab product was from 7.5 to $10 \mathrm{C}$ and $2.5 \mathrm{C}$ for a finite cylinder container. However, the case-studies carried out in their work did not include all the range of practical interest. Furthermore, the objective function was not adequate and the influence of the $\mathrm{D}_{\text {refq }}$-value on $\left(\mathrm{T}_{\mathrm{op}}\right)^{\text {ave }}$ was not considered (Silva et al. 1992a). To maximize quality in terms of volume average quality, the sterilization conditions must be more rigorous in order to accelerate the heat transfer into the product and decrease the difference of lag heating times through the whole container. 
TABLE 4.

VALUES FOR THE CONSTANTS IN EQ. (3) AND (4)

\begin{tabular}{|c|c|c|c|c|c|c|c|c|c|c|c|c|c|c|c|c|c|}
\hline Equantion & $a$ & b & c & d & e & 1 & g & h & 1 & 1 & k & 1 & $\mathrm{~m}$ & $n$ & 0 & p & $\begin{array}{l}\text { corr. } \\
\text { coef. }\end{array}$ \\
\hline 3 & 113.8 & 0.343 & 0.389 & 10.85 & -0.725 & -0.032 & -1.52 & 5.22 & -3.03 & 0.015 & 1.05 & .3 .86 & -0.0044 & 0.017 & .9 .10 & 1.94 & 0.988 \\
\hline 4 & 135.9 & 0.359 & 0.234 & 10.11 & 0.715 & .0 .040 & .0 .018 & 1.60 & 0.0024 & $5.93 e-6$ & 0.0027 & -0.0074 & $-1.22 E-5$ & $3.41 \mathrm{E} \cdot 5$ & -14.35 & 1.95 & 0980 \\
\hline
\end{tabular}




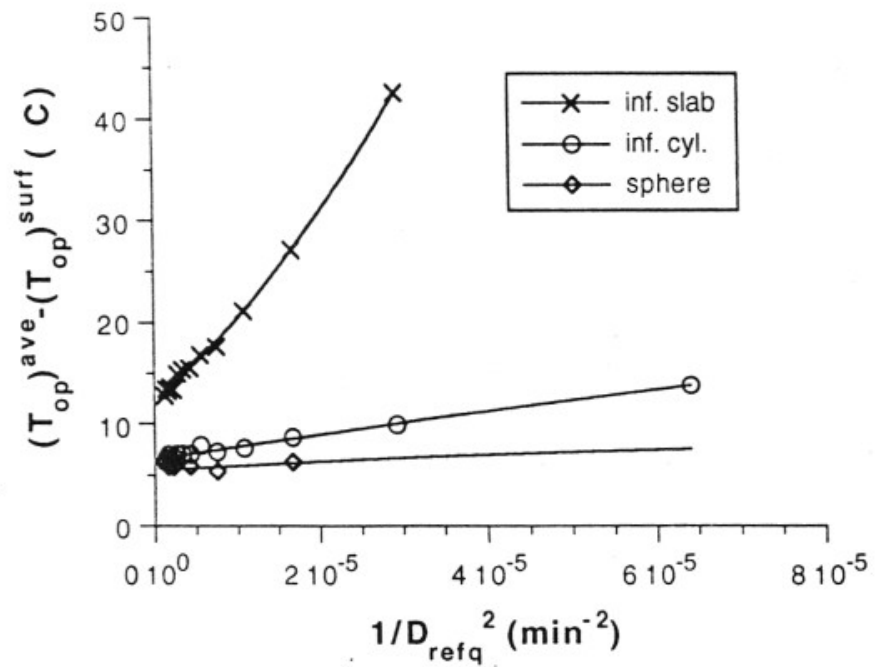

FIG. 10. DIFFERENCE BETWEEN $\left(\mathrm{T}_{\mathrm{op}}\right)^{\text {ave }}$ AND $\left(\mathrm{T}_{\mathrm{op}}\right)^{\mathrm{surf}}$, AS A FUNCTION OF $\mathrm{D}_{\text {refq }}-$ VALUE FOR $\mathrm{F}_{\mathrm{t}}=9 \mathrm{MIN}, \mathrm{z}_{4}=25 \mathrm{C}$ AND RF $=2.84 \mathrm{E}-5 \mathrm{~s}^{-1}$ AND Bi $=\infty$

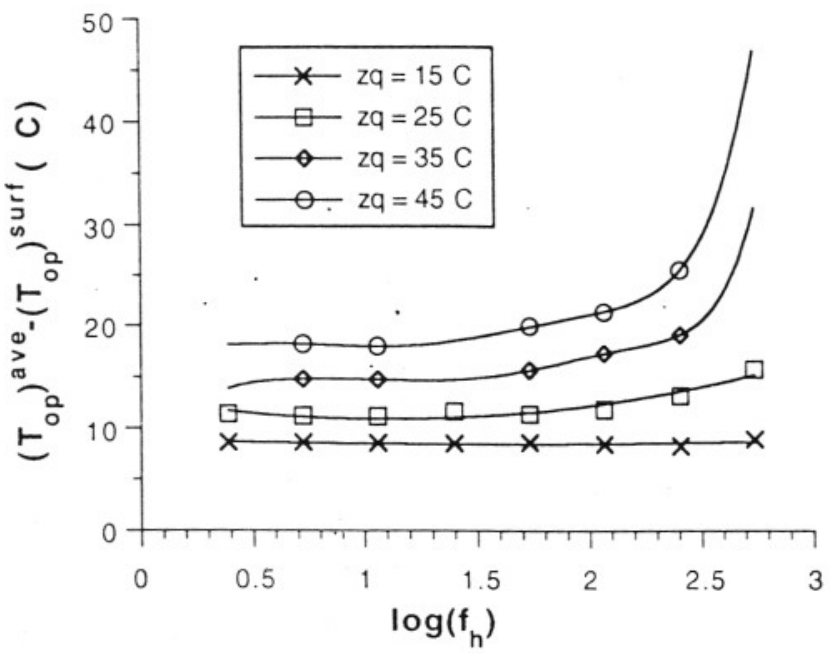

FIG. 11.,DIFFERENCE BETWEEN $\left(\mathrm{T}_{\mathrm{op}}\right)^{\text {ave }}$ AND $\left(\mathrm{T}_{\text {up }}\right)^{\text {surt }}$, FOR AN INFINITE SLAB PRODUCT, AS A FUNCTION OF $\mathrm{f}_{\mathrm{h}} \mathrm{FOR} \mathrm{D}_{\text {ref }}=485 \mathrm{MIN}$,

$\mathrm{F}_{i}=12 \mathrm{MIN}$ AND $\mathrm{Bi}=\infty$ 


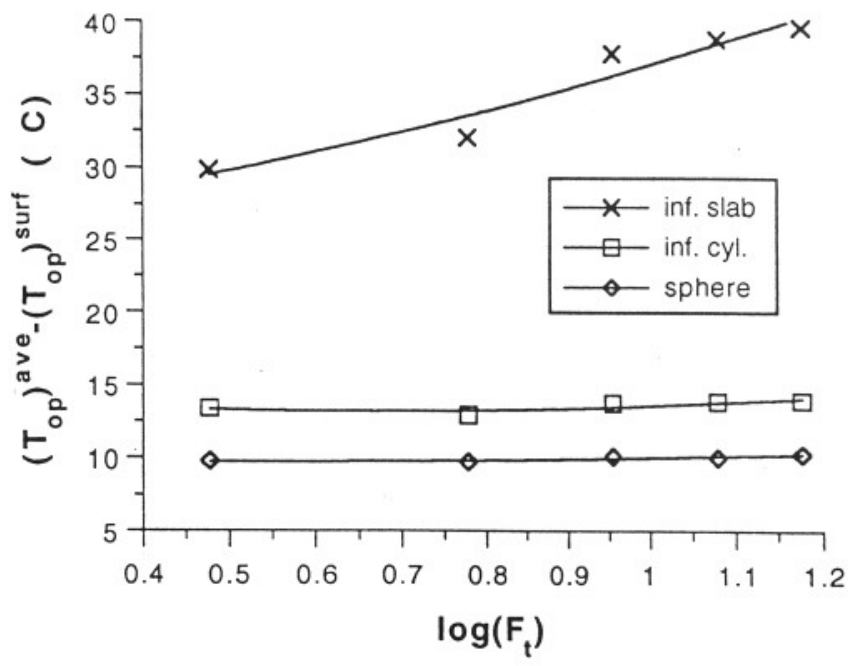

FIG. 12. DIFFERENCE BETWEEN $\left(\mathrm{T}_{\mathrm{op}}\right)^{\text {ave }}$ AND $\left(\mathrm{T}_{\mathrm{op}}\right)^{\text {surf }}$, AS A FUNCTION OF $\mathrm{F}_{\mathrm{t}}$-VALUE FOR $D_{\text {refq }}=605 \mathrm{MIN}, \mathrm{z}_{\mathrm{q}}=45 \mathrm{C}, \mathrm{RF}=2.84 \mathrm{E}-5 \mathrm{~s}^{-1} \mathrm{AND} \mathrm{Bi}=\infty$

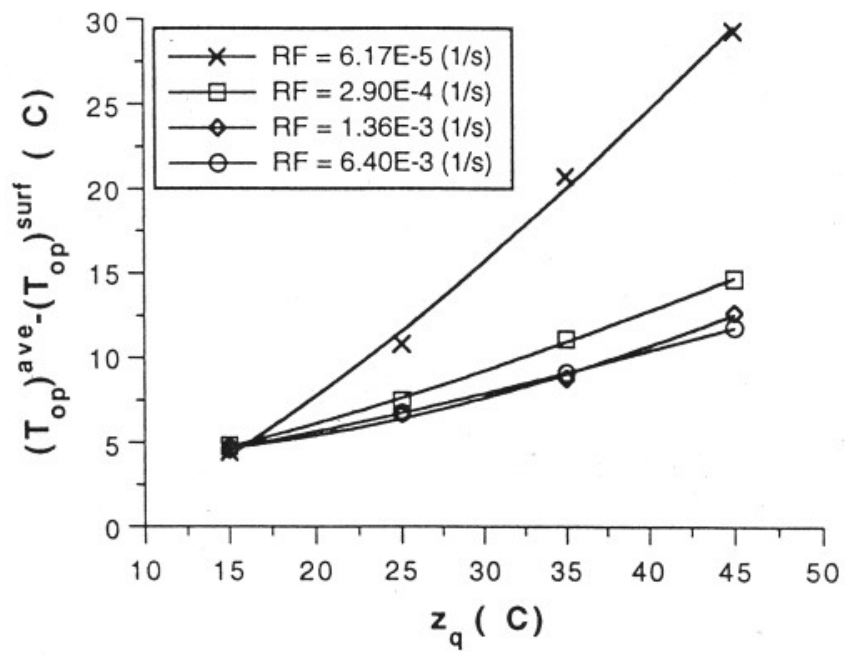

FIG. 13. DIFFERENCE BETWEEN $\left(\mathrm{T}_{\mathrm{op}}\right)^{\text {ave }}$ AND $\left(\mathrm{T}_{\mathrm{op}}\right)^{\text {surf }}$, FOR AN INFINITE CYLINDER PRODUCT, AS A FUNCTION OF $z_{4}$-VALUE FOR $D_{\text {refq }}=65 \mathrm{MIN}$,

$$
\mathrm{F}_{\mathrm{t}}=3 \text { MIN AND Bi }=\infty
$$




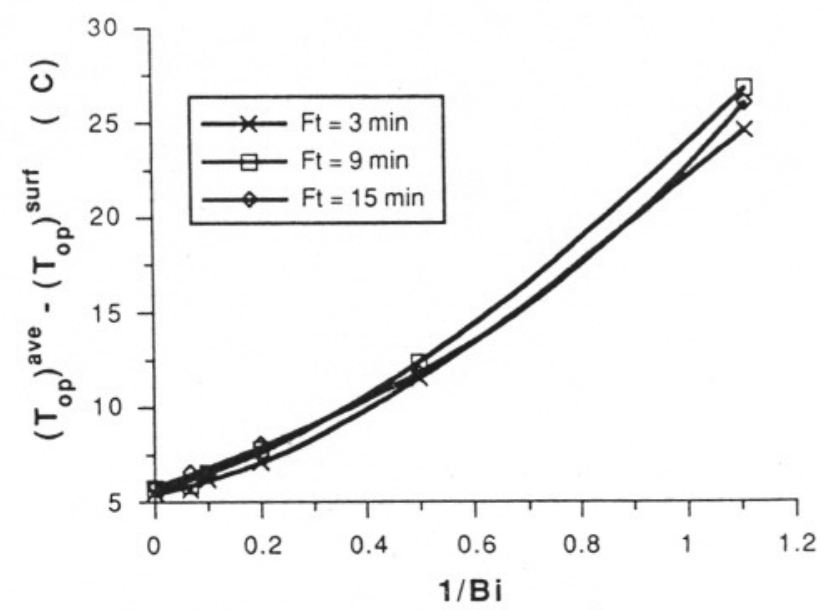

FIG. 14. DIFFERENCE BETWEEN $\left(\mathrm{T}_{\text {op }}\right)^{\text {ave }}$ AND $\left(\mathrm{T}_{\text {op }}\right)^{\text {surt }}$, FOR AN INFINITE SLAB PRODUCT, AS A FUNCTION OF Bi for $D_{\text {refq }}=605 \mathrm{MIN}, \mathrm{F}_{\mathrm{t}}=15 \mathrm{MIN} \mathrm{AND} \mathrm{z_{q }}=25 \mathrm{C}$

$\left(T_{o p}\right)^{\text {ave }}-\left(T_{o p}\right)^{\text {surf }}$ decreases with the $D_{\text {refq }}$-value (Fig. 10) and Biot number (Fig. 14), and increases with the heat penetration parameter $f_{h}$ (Fig. 11), $\mathrm{z}_{\mathrm{q}}$-value (Fig. 11 and 13), and $\mathrm{F}_{\mathrm{t}}$-value (Fig. 12). The geometry is also a parameter to consider, the difference between optimal temperatures increases from a spherical to an infinite slab shape container (Fig. 10 and 12). The selection of the optimum sterilization temperature to minimize volume average quality degradation is more important for food products that heat up slowly (this means products with low thermal diffusivities, large containers and heating medium conditions were the heat transfer coefficient is finite), which need to be sterilized more intensively (larger $\mathrm{F}_{\mathrm{t}}$-value), and with high rates of quality factor thermal degradation. These case studies are also the ones for which bigger differences between $\left(\mathrm{T}_{\mathrm{op}}\right)^{\text {ave }}$ and $\left(\mathrm{T}_{\mathrm{op}}\right)^{\text {surf }}$ are observed and where the optimum final retention is low.

Optimum surface quality temperatures are a linear function of: $\log \left(\mathrm{F}_{\mathrm{t}} / \mathrm{f}_{\mathrm{h}}\right)$ or $\log \left(\mathrm{F}_{\mathrm{t}} * \mathbf{R F}\right), \ln \left(\mathrm{z}_{\mathrm{q}}\right), 1 / \mathrm{Bi}, \mathrm{z}_{\mathrm{q}} / \mathrm{Bi}$ and $2^{(\mathrm{V} / \mathrm{A} . \mathrm{l}))}($ Table 2$)$, and do not depend on the $\mathrm{D}_{\text {refq }}$-value (Silva et al. 1992a). These linear relationships are not observed for optimum average quality temperatures [Table 3, Eq. (3) and (4)].

The conclusions that have been drawn are based on the assumption that the volume average or surface quality retentions to be optimized are for quality factors having the same degradation kinetics. However, this assumption may not be always true. The degradation rate of quality factors normally optimized at the surface (e.g., color) is usually faster than the kinetics for quality factors optimized in volume average terms (e.g., vitamins). A further extended study is needed to conclude about the validity of the above results for such a situation. 


\section{CONCLUSIONS}

The influence of $\mathrm{D}_{\text {refg, }}, \mathrm{z}_{\mathrm{q}}, \mathrm{f}_{\mathrm{h}}$ or $\mathbf{R F}, \mathrm{F}_{\mathrm{t}}$ and $\mathrm{Bi}$ on optimal conditions to maximize average quality retention was analyzed. A general relationship between optimal temperatures and all the relevant parameters was developed. The applicability of these formulae to two or three-dimensional food geometries has to be assessed.

Optimal temperatures to minimize surface quality degradation were compared with the corresponding ones for average quality. The selection of the optimum sterilization temperature to minimize volume average quality degradation is more important for foods that heat up slowly, need to be sterilized more intensively and with high rate of thermal degradation for the quality factor. In these situations differences between optimal temperature to maximize volume average quality and holding temperature to maximize surface quality are also more significant, and quality retention is low.

There is a need to study how optimal conditions for average quality affect surface quality and vice-versa. A new objective function might be considered.

\section{NOMENCLATURE}

\section{A Area $\left(\mathrm{m}^{2}\right)$}

Bi Biot number $\left(=h^{*} / / k\right)$ (dimensionless)

$\mathrm{dV}^{\prime} \quad$ Volume element $\left(\mathrm{m}^{3}\right)$

D Decimal reduction time (time required for the number or concentration of spores, microorganisms or quality factor to be reduced by a factor of 10 at a given temperature) $(\mathrm{min})$

$\mathrm{D}_{\text {ref }} \quad$ Decimal reduction time at the reference temperature $(\mathrm{min})$

$D_{\text {refq }}$ Decimal reduction time at the reference temperature, $T_{\text {refq }}$, for the nutrient or quality factor (min)

$\mathrm{f}_{\mathrm{h}} \quad$ Heat penetration parameter-slope factor of a heating curve (time required for the difference between heating medium temperature and food temperature to decrease by a factor of 10) $(\mathrm{min})$

$\mathrm{F}_{\mathrm{o}} \quad$ Sterility value at reference temperature $121.15 \mathrm{C}$ and $\mathrm{z}_{\mathrm{m}}=10 \mathrm{C}$ (equivalent exposure time at reference temperature received by the slowest-heating zone in the container with regard to the destruction of a microorganism whose thermal resistance is characterized by $\mathrm{z}_{\mathrm{m}}=$ 10C) (min)

$\mathrm{F}_{\mathrm{t}} \quad$ Target sterilizing value at reference temperature $121.15 \mathrm{C}$ and $\mathrm{z}_{\mathrm{m}}=$ 10C (min)

h Surface heat transfer coefficient $\left(\mathrm{W} /\left(\mathrm{m}^{2} \mathrm{~K}\right)\right)$

$\mathrm{h}_{\text {finite }} \quad$ Finite surface heat transfer coefficient $\left(\mathrm{W} /\left(\mathrm{m}^{2} \mathrm{~K}\right)\right)$

$\mathrm{h} \infty \quad$ Infinite surface heat transfer coefficient $\left(\mathrm{W} /\left(\mathrm{m}^{2} \mathrm{~K}\right)\right)$

k Thermal conductivity $(\mathrm{W} /(\mathrm{m} \mathrm{K}))$ 
1 Characteristic length (radius of an infinite cylinder or a sphere and half thickness of an infinite slab) (m)

$\mathrm{N} \quad$ Level of nutrients or quality factor at time $t$

$\mathrm{N}_{\mathrm{o}} \quad$ Initial level of nutrients or quality factor

$\left(\mathrm{N} / \mathrm{N}_{\mathrm{o}}\right)_{\text {ave }}$ Volume average quality retention

RF Reduced Fourier number $\left(=\alpha / 1^{2}\right)\left(\mathrm{s}^{-1}\right)$

t Time (s)

$\mathrm{t}^{\prime} \quad$ Total processing time (s)

$\mathrm{T} \quad$ Temperature $(\mathrm{C})$

$\mathrm{T}_{\mathrm{c}} \quad$ Temperature in the least-lethality spot (C)

$\mathrm{T}_{\mathrm{o}} \quad$ Initial temperature of the food $(\mathrm{C})$

$\mathrm{T}_{\text {op }} \quad$ Optimum processing temperature (C)

$\left(\mathrm{T}_{\mathrm{op}}\right)^{\text {ave }}$ Optimum processing temperature to maximize volume average quality retention $(\mathrm{C})$

$\left(\mathrm{T}_{\mathrm{op}}\right)^{\text {surf }}$ Optimum processing temperature to maximize surface quality retention (C)

$\mathrm{T}_{\text {ref }} \quad$ Reference temperature (C)

$\mathrm{T}_{\text {refm }} \quad$ Reference temperature for the microorganism (121.1 C)

$\mathrm{T}_{\text {refq }} \quad$ Reference temperature for the quality factor $(121.1 \mathrm{C})$

V Volume $\left(\mathrm{m}^{3}\right)$

$\mathrm{z} \quad \mathrm{z}$-Value (number of degrees Celsius required to reduce the $\mathrm{D}$-value by a factor of ten) (C)

$\mathrm{z}_{\mathrm{m}} \quad \mathrm{z}$-Value for the microorganism (C)

$\mathrm{z}_{\mathrm{q}} \quad \mathrm{z}$-Value for the nutrient or quality factor $(\mathrm{C})$

$\alpha \quad$ Thermal diffusivity $\left(\mathrm{m}^{2} / \mathrm{s}\right)$

\section{ACKNOWLEDGMENTS}

Authors C.L.M. Silva, F.A.R. Oliveira and P.A.M. Pereira acknowledge JNICT (Junta Nacional de Investigação Científica e Tecnológica).

\section{REFERENCES}

BANGA, J.R., PEREZ-MARTIN, R.I., GALLARDO, J.M. and CASARES, J.J. 1991. Optimization of the thermal processing of conduction-heated canned foods: study of several objective functions. J. Food Eng. 14, 25-51.

BARREIRO, J.A., PEREZ, C.R. and GUARIGUATA, C. 1984. Optimization of energy consumption during the heat processing of canned foods. J. Food Eng. 3, 27-37.

CHAU, K.V. and GAFFNEY, J.J. 1990. A finite-difference model for heat and mass transfer in products with internal heat generation and transpiration. J. Food Sci. 55, 484-487. 
HENDRICKX, M., SILVA, C., OLIVEIRA, F. and TOBBACK, P. 1992a. Optimization of heat transfer in thermal processing of conduction heated foods. In Advances in Food Engineering, (R.P. Singh and M.A. Wirakartakusumah, eds.) pp. 221-235, CRC Press, London.

HENDRICKX, M., SILVA, C., OLIVEIRA, F. and TOBBACK, P. $1992 \mathrm{~b}$. Optimizing thermal processes of conduction heated foods: generalized equations for optimal processing temperatures. In Food Engineering in a Computer Climate, St John's College, Cambridge, Mar. 30-Apr. 1, pp. 271-276.

HENDRICKX, M., SILVA, C., OLIVEIRA, F. and TOBBACK, P. 1993. Generalized (semi)-empirical formulas for optimal sterilization temperatures of conduction heated foods with infinite surface heat transfer coefficients. J. Food Eng. 19, 141-158.

HENDRICKX, M., VAN GENECHTEN, K. and TOBBACK, P. 1990. Optimizing quality attributes of conduction heated foods, a simulation approach. In Engineering and Food: Preservation Processes and Related Techniques, Vol. 2, (W.E.L. Spiess and H. Shubert, eds.) pp. 167-176. Elsevier Applied Science, London.

HOLDSWORTH, S.D. 1985. Optimisation of thermal processing - a review. J. Food Eng. 4, 89-116.

LUND, D.B. 1975. Effects of blanching, pasteurization and sterilization on nutrients. In Nutritional Evaluation of Food Processing, (R.S. Harris and E. Karmas, eds.) pp. 205-240, Van Nostrand Reinhold/AVI, New York.

LUND, D.B. 1977. Design of thermal processes for maximizing nutrient retention. Food Technol. 2, 71-78

LUND, D.B. 1982. Applications of optimization in heat processing. Food Technol. 2, 97-100.

MARTENS, T. 1980. Mathematical Model of Heat Processing in Flat Containers. Ph.D thesis, Katholieke Universiteit Leuven, Belgium.

NADKARNI, M.M. and HATTON, T.A. 1985. Optimal nutrient retention during the thermal processing of conduction-heated canned foods: application of the distributed minimum principle. J. Food Sci 50, 1312-1321.

OHLSSON, T. 1980a. Optimal sterilization temperatures for flat containers. J. Food Sci. 45, 848-852.

OHLSSON, T. 1980b. Optimal sterilization temperatures for sensory quality in cylindrical containers J. Food Sci. 45, 1517-1521.

OHLSSON, T. 1980c. Optimization of heat sterilization using C-values. In Food Process Engineering, pp. 137-145, Applied Science Publishers, U.K.

PFLUG, I.J. and ODLAUG, T.E. 1978. A review of $\mathrm{z}$ and $\mathrm{F}$ values used to ensure the safety of low-acid canned foods. Food Technol. 6, 63-70.

RIDGWAY, G. and BRIMELOW, C.J.B. 1990. Optimal food process design and control. Food Control 1, 4-5.

SAGUY, I. and KAREL, M. 1979. Optimal retort temperature profile in 
optimizing thiamin retention in conduction-type heating of canned foods. J. Food Sci. 44, 1485-1490.

SILVA, C., HENDRICKX, M., OLIVEIRA, F. and TOBBACK, P. 1992a. Critical evaluation of commonly used objective functions to optimize overall quality and nutrient retention of heat preserved foods. J. Food Eng. 17, 241-258.

SILVA, C.L.M, HENDRICKX, M., OLIVEIRA, F. and TOBBACK, P. 1992b. Optimal sterilization temperatures for conduction heating foods considering finite surface heat transfer coefficients. J Food Sci. 57 (3), 743-748.

SILVA, C.L.M, OLIVEIRA, F.A.R. and HENDRICKX, M. 1993. Modelling optimum processing conditions for the sterilization of prepackaged foods: a review. Food Control 4 (2), 67-78.

SILVA, C.L.M., OLIVEIRA, F.A.R. and HENDRICKX, M. 1994. Quality optimization of conduction heating foods sterilized in different packages. Int.

J. Food Sci. Technol. (In Press).

STATA. 1990. STATA - Reference Manual, Computing Resource Center, 1640 Fifth Street, Santa Monica, CA 90401.

TEIXEIRA, A.A., DIXON, J.R., ZAHRADNIK, J.W. and ZINSMEISTER, G.E. 1969a. Computer determination of spore survival distributions in thermally-processed conduction-heated foods. Food Technol. 23 (3), 78-80.

TEIXEIRA, A.A., DIXON, J.R., ZAHRADNIK, J.W. and ZINSMEISTER, G.E. 1969b. Computer optimization of nutrient retention in the thermal processing of conduction-heated foods. Food Technol. 23 (6), 137-142.

TEIXEIRA, A.A., ZINSMEISTER, G.E. and ZAHRADNIK, J.W. 1975. Computer simulation of variable retort control and container geometry as a possible means of improving thiamine retention in thermally processed foods.

J. Food Sci. 40, 656-659.

THIJSSEN, H.A.C., KERKHOF, P.J.A.M. and LIEFKENS, A.A.A. 1978. Short-cut method for the calculation of sterilization conditions yielding optimum quality retention for conduction-type heating of packaged foods. J. Food Sci. 43, 1096-1101.

THIJSSEN, H.A.C. and KOCHEN, L.H.P. 1980. Calculation of optimum sterilization conditions for packed conduction-type foods. J. Food Sci. 45, 1267-1272.

TUCKER, G. and HOLDSWORTH, D. 1990. Optimisation of quality factors for foods thermally processed in rectangular containers. In Process Engineering in the Food Industry. 2. Convenience Foods and Quality Assurance, (R.N Field and J.A. Howell, eds.) pp. 59-74, Elsevier Applied Science, London.

TUCKER, G.S. and HOLDSWORTH, S.D. 1991. Mathematical modelling of sterilization and cooking processes for heat preserved foods - applications of a new heat transfer model. Trans I ChemE 69, part C, 5-12. 